\title{
[ARTI GO RETRATADO] Abordagem sobre os diferentes processos de secagem empregados na obtenção de extratos secos de plantas medicinais
}

[RETRACTED ARTI CLE] Approach on different drying processes employed for obtaining dry extracts from medicinal plants

Silva, R.M.F.II*; Gomes, T.C.B.L.I ; Albuquerque, M.M.I ; Silva J unior, J .O.C.I I ;

Barbosa, W.L.R.I I; Rolim Neto, P.J .I

IDepartamento de Ciências Farmacêuticas, Universidade Federal de Pernambuco, CEP: 50740521, Recife-Brasil

IIFaculdade de Farmácia, Universidade Federal do Pará, CEP: 66.075-110, Belém-Brasil

A Revista Brasileira de Plantas Medicinais constatou uso indevido de informação em artigo de revisão publicado eletronicamente no no v14, n1 paginas 103-109, título Abordagem sobre os diferentes processos de secagem empregados na obtenção de extratos secos de plantas medicinais. SILVA, R.M.F.2*; GOMES, T.C.B.L.1; ALBUQUERQUE, M.M.1; SILVA JUNIOR, J.O.C.2; BARBOSA, W.L.R.2; ROLIM NETO, P.J.1.

Em concordância com os autores solicita a retirada do referido artigo. 
Abordagem sobre os diferentes processos de secagem empregados na obt nção de extratos secos de plantas medicinais

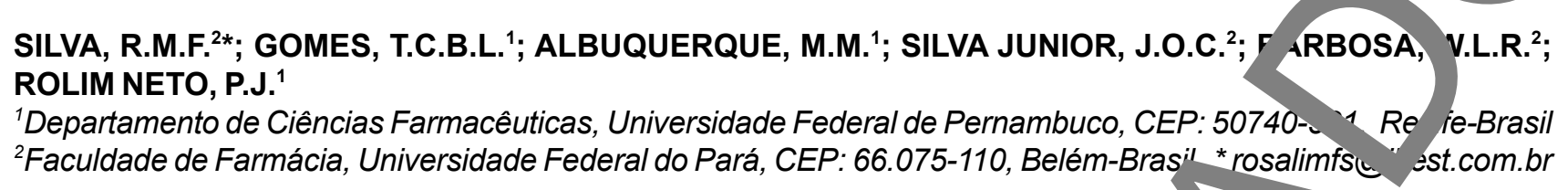

RESUMO: Na indústria farmacêutica de fitoterápicos, o extrał seco é Insiderado tecnologicamente viável para fins de produção em larga escala, $d$ à estabilì de física, química e microbiológica, além da facilidade de padronização do princı $\varsigma$ ativos. Entre as técnicas de secagem empregadas na preparação de extratos secos, encontra-- a nebulização ou spray-dryer, o leito de jorro, a liofilização e a evaporação rc tiva. A escolha do processo de secagem é motivada pela potencialidade dos diferentes equipá entu. ndores, na secagem de materiais presentes na forma líquida, no caso, soluções ext. tiv s de plantas medicinais, fornecendo um produto de alta qualidade e com investimento relativ nente baixo.

Palavras-chave: técnicas de secagem, plantas medic ais, fit farmacêutica

ABSTRACT: Approach on different drying p cesses emp yed for obtaining dry extracts from medicinal plants. In the pharmaceutic in a try of herbal medicines, the dried extract is considered technologically feasible for large-scale produ 'on, due to its physical stability, possibility of chemical and microbiological analyses ? d the ease of standardization of the active ingredients. Among the drying techniques used in th prepa tion of dry extracts are a mist or spray-dryer, the spouted bed, freeze-drying and rotary by the potential of different drying equipm. s and raterials present in liquid form, in this case, solutions of herbal extracts provid' an qua roduct and a relatively modest investment.

Key words: drying techniques nedic al plán, serbal medicine, dried extracts, pharmaceutical industry

Nas últimas décar «s, a Nução de fitoterápicos tem explorad novas pos ibilidades tecnológicas para a obtençã de extratos ecos. Isso decorre das vantagens apres tadas pr os extratos secos, quando comp? aos o. c.us fluidos. Os extratos secos vegr ais sãc ito mais adaptados às necessidades $\mathrm{d}$ terapcutica noderna, devido à facilidade de padro zação e $d$ ' manuseio, o que contribui para gara in nomogeneidade de preparações" arma uticas (Teixeira, 1996; De Paula et al., 1997 Runha et a 2001).

0. 'vfinição, extratos secos são preparações sólidas, pulver ntas ou granuladas obtidas por evap ração de e, ratos de plantas medicinais ad' 'onac is ou não de adjuvantes, apresentando o teor $c$ subst $\hat{y}^{\prime}$ cra otivas indicado na respectiva monografia (1. rm? opéia Brasileira, 1988).
Esse extrato seco é considerado tecnologicamente viável para fins de produção em larga escala, devido à estabilidade física, química e microbiológica, além da facilidade de padronização dos princípios ativos. Na indústria farmacêutica de fitoterápicos, o extrato seco é aplicado na preparação de comprimidos, cápsulas, granulados, pomadas e outras formas farmacêuticas, como produto intermediário. Entre outras vantagens, apresentam maior estabilidade e distribuição granulométrica dos constituintes da preparação (Cordeiro, 2000).

Na preparação de extratos secos, a adição de adjuvantes à solução extrativa melhora o rendimento e as características farmacotécnicas do pó obtido durante a secagem, sendo a adição indispensável para a maioria dos produtos desenvolvidos. Os adjuvantes devem caracterizar-se pela inércia 
química, inocuidade e termo-estabilidade (Teixeira, 1996).

Entre as técnicas de secagem empregadas com sucesso na preparação de extratos secos encontra-se a nebulização ou spray-dryer (Masters, 1979; Bassani, 1990; Broadhed et al., 1992; Teixeira, 1996; Souza, 2003), o leito de jorro (Souza, 2007), a liofilização e a evaporação rotativa (Sousa et al., 2007; Dutra et al., 2009), técnicas estas que serão descritas com destaque, para a aplicação na obtenção e padronização de extratos secos, para fins de utilização como insumo farmacêutico de interesse para a produção de fitoterápicos.

\section{Secagem em spray-dryer (ou secagem por nebulização)}

O processo spray-dryer consiste na atomização de uma mistura diluída sólido-fluido em corrente gasosa aquecida que promove a evaporação do solvente, levando a um produto seco. Embora seja tecnologia cara que necessita de altos investimentos em instalações e operações, muitas são as razões pelas quais a mesma é amplamente utilizada (Wendel \& Celic, 1998). Essas razões incluem a produção de materiais com propriedades físicas desejadas, a capacidade de processar diferentes tipos de matériasprimas e a flexibilidade da operação. Opera em temperaturas de gás de entrada relativamente baixas com eficiência similar a outros tipos de secager. direta, sendo que o produto seco obtido apresenta características homogêneas (Isono et al., 19 ). tempo de residência do material no interior de câmar: de secagem é relativamente pequeno, o s tor $d$ esse equipamento adequado para a secage. de produtos termo-sensíveis, como os extratos vegetan A qualidade do pó obtido é baseada em uma série de propriedades dependentes das var vels u rocesso utilizadas. Em geral, o conteúdo e umidadt inal, o índice de solubilidade e a densid de aparente ão de fundamental importância (Souza, 103).

O spray-dryer é fr nterm sado em processos industriais $c$ e env $m$ a geração e secagem de gotículas íquidz, $\mathrm{P}$ s cinos secos, granulados ou aglomer los podem ser produzidos continuamente pele ecag de sr dções, emulsões ou suspensões. ?s pu nroduzidos por spray-dryer reúnem padrõf elevados qualidade com respeito à granulor a do produto, umidade final, homogene, ade, ac idade e forma, sendo que estas características podem - alteradas por modificações nos pa ame os do processo. O pó obtido por esta tecn ogia é … ularmente apreciado devido à alta fluia ser oque esta propriedade pode ser atribuída à forma córica das partículas obtidas (Remili et al., 1994).

רconrodutos obtidos por spray-dryer são, em g ral mais solúveis e concentrados. O processo envolve extração primária da planta com s ventes apropriados como soluções de etanol-á ua em diferentes proporções. O extrato bruto e. ão é concentrado e seco em spray-dryer a

variando entre 100 e $200^{\circ} \mathrm{C}$ (Souza, J03).

Uma vantagem do proce o spray-dry ré que a secagem ocorre em condiço assép cas evitando possíveis contaminações "the o processamento, podend su cumir que a contaminação bacterian. fi al procede essencialmente da p'inta o hal ou após o processamento, pelar anipulação umana.

Remili et ar. 1994) Estudaram as contaminações miurobiana om extratos secos de plantas medicinais obtidas pur spray-dryer e a influência do $\mathrm{pr}$ na qualidade do produto. Como este material é $t$ sencr inte destinado ao uso oral, existem limites ${ }^{7}$ Citáveis de contaminação microbi Este autores constataram que, qualite vame ite os tratos produzidos por spraydrye apres nta. baixa contaminação, mas o conte. ' ' stal de bactérias viáveis permaneceu

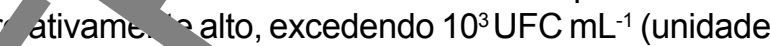
rmadora de 0 iônia/mililitro) em 35 das 82 amostras anc. 'adas.

umidade é variável interessante no processo de desidratação e é ótimo parâmetro a ser medido durante a operação. A temperatura é medida secr dária que não pode ser a causa de diferenças hic oscópicas em produtos, seguida da mudança da mposição e mudanças na umidade do ar de entrada. Medidas da umidade do produto após o processo são indicadoras da eficiência do processo de desidratação.

A maioria dos equipamentos de secagem faz medidas da temperatura, vazão de alimentação, vazão e umidade do gás de entrada. Medidas da umidade do ar de exaustão podem ser usadas em vários tipos de análises para predizer e melhorar a eficiência incluindo balanço de massa, balanço de energia, análise higroscópica, análise estatística e/ou simulação do processo.

Extratos de Amaranthus betacyanin foram secos em spray-dryer por Cai \& Corke (2006) usando uma série de maltodextrinas e amido como adjuvantes. Analisaram a influência das temperaturas de ar de entrada/saída e a concentração de sólidos da solução de alimentação nas características finais do produto. Constataram que elevadas temperaturas do ar de entrada/saída causaram grande perda de betacianina (pigmento) durante a secagem, afetando levemente a estabilidade durante a armazenagem do produto.

O emprego de adjuvantes tecnológicos como o amido, a celulose microcristalina, a $\beta$-ciclodextrina, o dióxido de silício coloidal, etil-celulose e gelatina foram avaliados por Teixeira (1996). No entanto, o 
emprego resultou na obtenção de produtos com baixíssimos rendimentos devido principalmente a aderência do extrato nas paredes da câmara de secagem. Uma exceção foi observada nos produtos obtidos a partir do dióxido de silício coloidal como já relatado em outros trabalhos (Bassani, 1990; Senna, 1993; Senna et al., 1997; Cordeiro, 2000; Runha et al., 2001).

Três combinações de adjuvantes de secagem [dióxido de silício coloidal, celulose microcristalina + dióxido de silício coloidal (1:1) e $\beta$-ciclodextrina + dióxido de silício coloidal (1:1)] foram analisados por De Paula et al. (1998) na obtenção de extratos secos nebulizados de marcela (Achyrocline satureioides). Os extratos secos foram incorporados em base para pomada. Foram avaliadas a influência dos adjuvantes de secagem nas características das formulações, como espalhabilidade, índice de oleosidade, viscosidade e $\mathrm{pH}$. Os resultados indicaram a influência dos adjuvantes de secagem nos parâmetros físicos das formulações em diferentes níveis, apesar de todas terem mantido o comportamento plástico. A presença apenas de dióxido de silício coloidal no extrato seco concedeu à pomada baixo valor no índice de oleosidade e área de espalhabilidade intermediária. A redução no conteúdo de dióxido de silício coloida' e substituição desta parte por celulose microcristal' a ou $\beta$-ciclodextrina aumentou o índice de oleosir de e levou à melhora na espalhabilidade da poma

Casadebaig et al. (1989) avaliaram don adjuvantes tecnológicos, a goma arábica r $\mathrm{\rho}$ a 200, na preparação de extratos secos e Fra) excelsior. Extratos aquosos e alco "cos oram preparados e submetidos ao processo de agem. Foram realizadas análises de distribu ão granulométrica, testes de estabilidade do pó seco em atmosfera de umidade rativa ontrolada e cromatografia em camada $d$ igada do $p$ duto final. Os resultados indicaram $q$; o pó proc zido pelo extrato alcoólico foi de qualida superior o pó obtido do extrato aquoso. roma obtidos indicaram que o roces de secagem por nebulização não (odific as ustâncias ativas presentes nos extr. os. A pres hça de adjuvantes tecnológicos $r$ rod . seco a com que o tempo de validade'seja 'mentado. Com os resultados apresente os, pode- verificar que adjuvantes tecnolóc $\mu$ se mostram de grande importância na produç o de $\epsilon$, atos secos.

\section{Len de jorro}

on tipo de secador foi desenvolvido em 54, or Glisnler e Mathu, sendo, inicialmente projo do para a secagem de grãos de trigo (Marreto, 2006).

O leito de jorro tem por finalidade promover o ir imo contato entre um fluído e partículas relativamente grandes (acima de $1,0 \mathrm{~m}$ ), as quais apresentam fluidização de baixa qua lade. Esta técnica é recomendada para a secagem a materiais granulares, pastas e suspensõ anum, e revestimento de partículas, e re outra (Souza, 2003).

No caso da secagem, à tilização do leito de jorro tem sido difundida devido às re rísticas de alta taxa de circulaçã un tículas mertes e da uniformidade da tempera ra $r$, Ier. Outro fator positivo desta técnic é o ba custo de construção, manutenção e opf ação do eq yamento. Patel et al. (1986) mencion $n$, em secádor de leito de jorro, os custos de capital sâu roximadamente a metade do custo de um secador spra, além de ocupar espaço menor.

O. qime 0 é estabelecido em leito de partículas so $d$ o por meio da injeção de fluído (ger- nte ar) ר parte inferior verticalmente através de inico onto cL diâmetro é reduzido em relação diâm $\mathrm{O}$ a -ito, ocorrendo a formação de canal pr ar ncial como consequência das regiões distint

- .egião central (canal preferencial): ocorre transporte pneumático das partículas devido à gra. ve velocidade do fluído.

- Região de jorro (fonte): região acima do leito onde as partículas advindas da região central ovimentam-se em regime desacelerado, como em uma fonte, caindo na região anular.

- Região anular (deslizante): nesta região, as partículas caem da região de jorro e deslizam para baixo, operando como um leito deslizante.

Muitos autores, no entanto, definem como região de jorro ao conjunto região central-região de jorro (Oliveira, 2006).

Os principais parâmetros fluidodinâmicos no estudo dos regimes de jorro são a velocidade mínima do jorro, a altura máxima de jorro estável e a perda de carga em função da velocidade do ar. A velocidade mínima do fluído necessária para manutenção do regime jorro é função das propriedades dos sólidos, da geometria do leito e do próprio fluído. Os valores da velocidade mínima do jorro podem diminuir com o aumento do diâmetro da câmera de secagem e com a diminuição da altura do leito fixo de sólidos. A altura máxima de jorro estável é a altura máxima de partícula inertes, acima da qual não se observa a ocorrência do regime de jorro e sim fluidização de má qualidade. A perda de carga em função da velocidade do ar é gerada pela elevada demanda energética necessária para estabelecer o regime de jorro (Marreto, 2006).

O regime fluído dinâmico único, observado neste tipo de equipamento, propicia inúmeras vantagens durante as aplicações. A excelente mistura de sólidos e o intenso contato fluído-sólido permitem 
secagem segura e eficiente de materiais termossensíveis.

Segundo Mathur \& Epstein (1974), existem basicamente três geometrias de secadores de jorro (cônica, cone-cilíndrica e retangular). Nem todo leito de jorro apresenta as três regiões descritas bem definidas.

Os secadores de jorro dividem-se em dois grupos principais - o JSB (Jet Spouted Bed) e o CSB (Conventional Spouted Bed). A diferença entre esses dois grupos está no diâmetro da entrada, que para o JSB é superior, e na porosidade do leito, que para o CSB é inferior a $85 \%$, e para o JSB é superior.

Souza (2007) investigou o potencial tecnológico e econômico do processo de secagem em leito de jorro, para a produção de extratos secos padronizados de plantas medicinais brasileiras utilizando como modelo experimental a Bauhinia forficata Link. Ensaios de secagem com diversos adjuvantes apontaram o dióxido de silício coloidal como o responsável pelos melhores resultados, sendo o material de escolha para os ensaios seguintes. Os ensaios de secagem realizados em duas configurações de leito de jorro (convencional e com instalação de tubo draft) foram delineados por meio de planejamento composto central. Os resultados deste trabalho indicam a viabilidade técnica e econômica do processo em leito de jorro para a obtenção de extratos secos de plantas medicinais despontando como um processo alternativo frente ao spray-dryer comumente usado nas indústri oc a processamento fitoterápico.

\section{Liofilização}

A liofilização é um processo que consis de três etapas. A primeira etapa é o congelamento do produto, de modo que a água pr sente. material seja convertida em gelo. Na se inda etapá o gelo formado durante o congelame to é remov lo do material pela conversão direta do tado sól o para vapor num processo den ado - ação. No terceiro passo, a água $c$ e aind r rmanece ligada fortemente aos solutos, enomi ada yua adsorvida, é convertida em vapor emovida c produto, num processo chamado ssol (Jal , 1999). Para isto faz-se necessár's qu zona da temperatura de sublimação se abaixo do onto triplo (num gráfico de pressão y temperatura, é o ponto onde há a coexistênc das tr fases - sólida, líquida e vapor).

Congelamen é a principal etapa, deste proces $0, p_{2} s$ dela depende o desempenho global da lic ização ' do à forma dos poros; a distribuição do ta anb dos poros; da conexão entre as redes de poros camada seca formada pela sublimação da água ou u ubstância aquosa congelada durante ' Seu n nrimária; a dependência do processo de i. filiz ção com os cristais de gelo formados durante o estágio de congelamento, tendo influência, mbém, na consistência do produto final, cor e rete cão de aroma (Boss, 2004).

Quando as estruturas dos

pequenas e descontínuas a taxa de ansferêl. a de massa do vapor d' água para a amada se l é limitada. Por outro lado, se o tamanho 's denc tes dos cristais de gelo forem apropriados e c. "c' rrsão homogênea da solução congt un ser realizada, a taxa de transferência de má sa $d$ vapur d'água para a camada seca po ser an o produto pode ser secado mais rapid nente. $\mathrm{O}$. todo e a taxa de liofilização, bem cor oc. רrma da scu ução contida e natureza do procuto sâu ríticos no curso da liofilização porque eles afetam c,axa de secagem e qualidade do $p$ to (Boss, 2004).

Segun 'O Ar $c$ et al. (1995), o congelamento len. $\left(1,-100^{\circ} \mathrm{C} \mathrm{min}{ }^{-1}\right)$ é prejudicial para as célul rque opicia a formação de grandes cristaic de ge o que á ós a sublimação da água ou da s ostân a á ssa podem causar prejuízos mecân 's estrutura das células como a membrana $r$ asmática. ' congelamento "ultraswift" $\left(1000^{\circ} \mathrm{C} \mathrm{min}{ }^{-1}\right)$ resultado queda brusca de pressão ou ter. sratura. Em consequência desta espécie de choquu equenos cristais de gelo são formados e distribuídos uniformemente sem afetar a estrutura das células. Este tipo de congelamento não só facilita o proc sso tecnológico como intensifica a desidratação. O ongelamento "ultraswift" ou auto congelamento é dicado nos casos em que os materiais têm baixa umidade. Para materiais com alta umidade faz-se, primeiramente, um congelamento inicial.

Este método de desidratação tem como objetivo preservar a qualidade do produto. Neste processo, a rápida transição das fases minimiza várias reações de degradação que ocorrem durante a secagem como a reação de Maillard, desnaturação de proteínas e reações enzimáticas (Boss, 2004).

As condições de procedimento, como baixa temperatura, pressão reduzida, ausência da fase líquida intermediária eliminam em grande parte os fatores de alteração e de desnaturação. É um método de preservação no qual são completamente interrompidas todas as atividades bioquímicas.

As bactérias não são exterminadas por este tipo de secagem, mas a proliferação não é possível no material seco. Após a secagem, as atividades das enzimas são inativadas porque não há água no meio e as reações químicas oxidativas ou não-oxidativas ocorrem em pequena quantidade, trazendo um resultado satisfatório (Boss, 2004).

O produto seco obtido, de aspecto poroso, friável, possui caráter liófilo, particularmente, uma avidez pela água que possibilita a reconstituição rápida e integral da solução ou da pseudo-solução inicial. A liofilização, apesar de ser processo caro, é 
utilizada como meio de estabilização e conservação corpos ou misturas frágeis, preparações assépticas e produtos biológicos (Jales, 1999).

Ishikawa et al. (2008) avaliaram o extrato liofilizado das folhas de Plinia edulis quanto ao perfil fitoquímico e à atividade antimicrobiana. A triagem fitoquímica evidenciou a presença de substâncias de interesse farmacológico tais como flavonóides, taninos, saponinas e terpenóides. No entanto, o extrato não inibiu o crescimento de Aspergilus niger, Candida albicans, Escherichia colie Staphylococcus aureus na concentração de até $1.000 \mathrm{mg} \mathrm{mL}^{-1}$.

Silva et al. (2001) comprovaram que a liofilização foi eficiente para conservar as sementes de ipê-rosa (Tabebuia heterophylla) nos ambientes não controlados e de câmara seca, mas desnecessária para o armazenamento em câmara fria. As sementes não liofilizadas, armazenadas em câmara fria, conservaram melhor a qualidade fisiológica do que as liofilizadas, armazenadas nos ambientes não controlados e de câmara seca.

Há diversos tipos de liofilizadores.

- Liofilizador tipo bandeja: é o mais utilizado. Existem dois tipos principais que diferem de acordo com o condensador utilizado. Os condensadores podem ser colocados dentro da câmara, ou condensador localiza-se numa câmara separa a conectada por tubos. Este tipo de equipam ito proporciona dificuldades em trabalhar com pro tos farmacêuticos, como ampicilina, devido à dificuldaa em manter o produto estéril. Porém possui z arn gem de ser mais econômico no que diz respe $s$ à ene

- Multibatelada: O fluxo de ass? e as operações de manuseio do produto são des tínuos; devido às características do processo.

- Túnel: A secagem ocorre em grande câmara de vácuo em forma de túnel ride roduto a ser secado entra, na forma con elada, sob bandejas dispostas em vagões ou es iras que atr vessam a câmara. Este tipo de equip mento $n$ s trabalha simultaneamente com antes, O sistema de refrigeração ope norm? snte com amônia. $O$ aquecimento da cor nte a $\checkmark$ cuo ruporciona diversas vantagens como o a $\mathrm{o}$ calor late te de condensação e o controle da mpe, ura nr pressão (Mujundar, 2006). Conf ' me s sumenta o volume da produção, aumenta- apenas comprimento do túnel e introduz o va bomba de vácuo. Este equipamento utiliza ciclos a pressão que traz em vantagens suficientes para ompensar o alto custo do eq par nto. O tempo de secagem diminui $30 \%$ em r. mpare an equipamentos que trabalham a N ssã constante (Lichtfield et al., 1981).

- Liofilizador continuo: As condições de operaça ão constantes e por isso de fácil controle, r. menor mão-de-obra e supervisão. O uso é ito interessante para estruturas que trabalham com um único produto ou que a alimentaçã provém de processo contínuo. Estes secadores cc tínuos são mais econômicos que os secadores em telada.

- Liofilização por micro-

desvantagens o alto valor com re ç̧ão ao p co desta forma de energia, é de difícil c trole porqu a água tem constante dielétrica maior que ' ' gelo $e$,ualquer ponto onde tenha ocorrido fusão do ge. " sre perda de calor, além de não t s... tipo ue secador disponível em escala indus ial.

O alto custc do proc $o$ de liofilização pode ser compensad pela nâ necessidade de manuseamento $c$ ocagem as produto em local refrigerado e tainbém qu. do o produto tem alto valor agregado.

\section{Evapc רção iva (Rotaevaporador ou Rotavapor) \\ Q evap rador rotativo é um equipamento em qu seco seque ncentrar o extrato por evaporação - soly nte, nde a solução a concentrar é cu. 'n' mente agitada por rotação imposta pelo motor e os va. vres de solvente libertados são condensados, passando $m$ seguida o condensado a balão no qual solvente poderá ser recuperado (Pombeiro, 2003). G七. 'mente, são utilizados pequenos volumes de extratos, a temperaturas entre 30 e $40^{\circ} \mathrm{C}$.}

Sousa et al. (2007) investigaram e unfirmaram os efeitos analgésico e anti-inflamatório da Posoqueria acutifolia. Após submeterem galhos deste vegetal à secagem a $50^{\circ} \mathrm{C}$, sob ventilação forçada, o material botânico foi triturado e pulverizado, e o extrato metanólico obtido por maceração estática durante três semanas com dez trocas de solvente. Após remoção do metanol por rotaevaporação, o extrato bruto seco foi solubilizado em dimetilsulfóxido (DMSO) $1 \%$ (v/v) em solução salina para avaliação das atividades farmacológicas.

A cicatrização de queimaduras cutâneas em coelhos, com aplicação tópica de cremes à base de fração hexânica obtida das sementes de Pterodon emarginatus, foi avaliada e confirmada por Dutra et al. (2009). As sementes foram trituradas e submetidas à extração utilizando aparelho de Soxhlet. Após o acondicionamento das sementes ao cartucho e adaptação do balão de fundo redondo, a amostra foi submetida a extrações sucessivas com hexano, por $24 \mathrm{~h}$, até atingir o esgotamento do solvente. A fração hexânica foi submetida à rotaevaporação, em temperatura de $50 \pm 5^{\circ} \mathrm{C}$, até eliminação completa do solvente.

Atualmente, o extrato seco é a forma preferida pelas indústrias farmacêuticas, principalmente pela maior concentração, estabilidade e facilidade de padronização dos princípios ativos presentes nas plantas. Esses fatores aumentam o valor agregado do produto, e contribuem também no atendimento 
das indústrias a Resolução da Diretoria Colegiada (RDC) o 48, da Agência Nacional de Vigilância Sanitária, de 16 de março de 2004, que visa controlar e monitorar a produção indiscriminada de produtos vegetais no Brasil, estabelecendo critérios rígidos para o registro desses tipos de produtos.

A escolha do processo de secagem é motivada pela potencialidade dos diferentes equipamentos secadores.

A escolha do tipo de secador passa por análise do tipo de partícula a ser seca, da capacidade de produção, eventual necessidade de recuperação de solvente e demanda energética do processo, levando-se em consideração a relação custo/benefício.

\section{REFERÊNCIA}

ADAMIEC, J. et al. Handbook of Industrial Drying. Nova lorque: Marcel Dekker, 1995. p.775-808.

BASSANI, V.L. Valorisation de formes galeniques vegetales desalcoolisation et concentration de solutions extratives sur membrane d'omose inverse, 1990. 261p. Tese (Doutorado) - Faculté de Pharmacie, Universitié de Montpellier, Montpellier.

BOSS, E.A. Modelagem e otimização do processo de liofilização: aplicação para leite desnatado e café solúvel. 2004. 129p. Tese (Doutorado) - Faculdade de Engenharia Química, Universidade Estadual de Campinas, Campinas.

BRASIL. Ministério da Saúde, Agência Nacional da Vigilância Sanitária, Resolução da Diretoria Cole no 48 , de 16 de março de 2004. Aprova o regu' mente técnico sobre o registro de medicamentos fito rápico Diário Oficial da República Federativa do Brası, ' 'จs' a, 2004.

BROADHEAD, J.; ROUAN, S.K.E.; RHODES, C.T. Th spray drying of pharmaceuticals, Drug Development and Industrial Pharmacy, v.18, n.11-12. 1992. CAI, Y.Z.; CORKE, H. Production ar properties ispraydried Amaranthus betacyanin pigm its. Journal Food Science, v.65, n.7, p.1248-52, 200

CASADEBAIG, J. et al. Phys chem al and pharmacological properties spray driea powders from Fraxinus excelsior if if ext c Journal of Ethnopharmacology, v.2 , n.2, p.211-6 Ty89.

CORDEIRO, D.S. Proc cão de e rato seco de Maytenus ilicifolia artius - $\mathrm{Ro}^{\prime}$ o pelo Processo Leito de Jorro, 000 . Dissertação (Mestrado) Faculdade de rências nacêuticas de Ribeirão Preto, Univers de de São Pâulo, Ribeirão Preto.

DE PAULA 1.C. al. Development of ointment formulations prepare w ith Achyrocline satureioides spray dri tracts. Drug Development and Industrial Pharm cy, v. 4 n.3, p. 234-41, 1998.

DE $Y$,ULA, o., TROVICK, P.R. Desenvolvimento tecno. ricr de forma farmacêutica plástica contendo extrato $s$ nebulizado de Achyrocline satureioides (I AM.) DC. C yositae. Caderno de Farmácia, v.13, n.2, 7.I. 1997.

VTR , R.u. et al. Efeito cicatrizante das sementes de
Pterodon emarginatus Vogel em modelos de úlceras dérmicas experimentais em coelhos. Latin $A$ ierican Journal of Pharmacy, v.28, n.3, p.375-82, 2009 Farmacopéia Brasileira. 4.ed. São Paulo ^ndrei, ne p. IV.7

HARBONE, J.B. Phytochemical me ods. A gur to modern techniques of plant analysis. Third edition Ed. Chapman \& Hall. 1998. p.6.

ISHIKAWA, T. et al. Morphornatomic as, and phytochemical screening of $F$, 'a dic (Vell.) Sobral (Myrtaceae). Revista Bras ira at iências Farmacêuticas, v.44, n.3 .515-2 08 .

ISONO, Y.; ARAYA, G.; JSHINO, Immobilization of Saccharomyces cerey for ethano ermentation on $\gamma$-alumina particles using spray-dryer. Process Biochemistry, v.30, n.8, p.743- 1995.

JALES, S.T.L. Avaliação da atividáde microbiológica e tecnologia de nan dormas farmacêuticas cápsulas e flaco tes and Zymomonas mobilis. 1999. 103p. Dis @ ação (Mestrado - Área de Concentr em Pro 'ção e Controle de Medicamentos) - Depar ment de Ciề as Farmacêuticas, Universidade Feder, de $P f$ ran "

LICh. "ELD R.J., LIATIS, A.I., FARHADPOUR, F.A. Cycled $p$ ssure a near - Optimal pressure policies for a eeze dryer. urnal of Food Technology, v.16, p.6371981.

MAn FTO, R.N. Estudo da técnica de leito de jorro convem nal para secagem de microcápsulas de caseína e pectinas. 2006. 199p. Tese (Doutorado) Faculdade de Ciências Farmacêuticas de Ribeirão de Prete Universidade de São Paulo, Ribeirão Preto.

MA IERS, K. Spray drying handbook. $3^{\text {td }}$, London: G orge Godwing Ltd., 1979. 687p.

wATHUR, K.B.; EPSTEIN, N. Spouted beds. London: Academic Press. 1974. 304p.

MUJUMDAR, A.S. Handbook of industrial drying. Thrid edition. Ed. CRC Press. 2006. 1312p.

OLIVEIRA, E.O. Secagem de Spirulina platensis: análise das técnicas de leito de jorro e camada delgada. 2006 . 92p. Dissertação (Mestrado- Área de concentração em Engenharia e Ciência de Alimentos) - Departamento de Química, Fundação Universidade Federal do Rio Grande, Rio Grande.

POMBEIRO, A.J.L.O. Técnicas e operações unitárias em química laboratorial. 4.ed. Ed. Fundação Calouste Gulbenkian. 2003. p.249.

PATEL, K. et al. Spouting behavior of wet solids. Drying'86, New York: Hemisphe-Publ.Co.,1986, p. 415-420.

REMILI, H.; BOUSSARD, P.; DEVLEESCHOUWER, M. Microbiological quality of spray-dried pharmaceutical plants extracts. European Journal of Pharmaceutical Sciences, v.1, p.265-8, 1994.

RUNHA, F.P. et al. Production of dry extracts of medicinal Brasilian plants by spouted bed process: development of the process and evaluation of thermal degradation during operation. Trans IChemE. v. 79, Part C, September, 2001. SENNA, E.M.T.L. Desenvolvimento de extratos secos nebulizados de Achyrocline satureioides (LAM.) DC. Compositae (Marcela), 1993. 140p. Dissertação (Mestrado) - Universidade Federal do Rio Grande do Sul, Porto Alegre.

SENNA, E.L. et al. Preparation and charactherization of 
spray-dried Powders from Achyrocline satureioides (LAM.) DC. extracts., Phytoterapy Research, v.11, p.123-7, 1997. SILVA, A. et al. Liofilização e armazenamento de sementes de ipê-rosa Tabebuia heterophylla (A.P. Candolle Britton) - Bignoniaceae. Revista Brasileira de Sementes, v. 23, n.1, p.252-9, 2001.

SOUSA, O.V. et al. Efeitos farmacológicos e toxicológicos do extrato Posoqueria acutifolia Mart. (Rubiaceae) em roedores. Revista de Ciências Farmacêuticas Básica e Aplicada, v.28, n.1, p.51-6, 2007.

SOUZA, C.R.F. Estudo comparativo da produção de extrato seco de Bauhinia forficata Link pelos processos spray-dryer e leito de jorro. 2003. 208p. Dissertação (Mestrado) - Universidade de São Paulo, Ribeirão Preto.
SOUZA, C.R.F. Produção de extr os secos padronizados de plantas medicinais bras iras: estudo da viabilidade técnica e econômica do proct so em leito de jorro. 2007. 219p. Tese (Doutoradol Fac. hdo Ciências Farmacêuticas de Ribeirã ,reto, iversidade de São Paulo, Ribeirão Preto,

TEIXEIRA, H.F. Avaliação da in ûncia de ar ıvantes farmacêuticos sobre as característica 'sicas uímicas, tecnológicas e farmacolóqicas de $t$. os secos nebulizados de Achyroch (Lam.) DC. Compositae - Marcela, Cade o dr rarm. cícia, v.13, n.2, p.151-2, 1997.

WENDEL, S.; CELIY M. Uma vis o geral sobre o uso da tecnologia de spra ving. harma utical Technology, v.5, p.32-43, 19

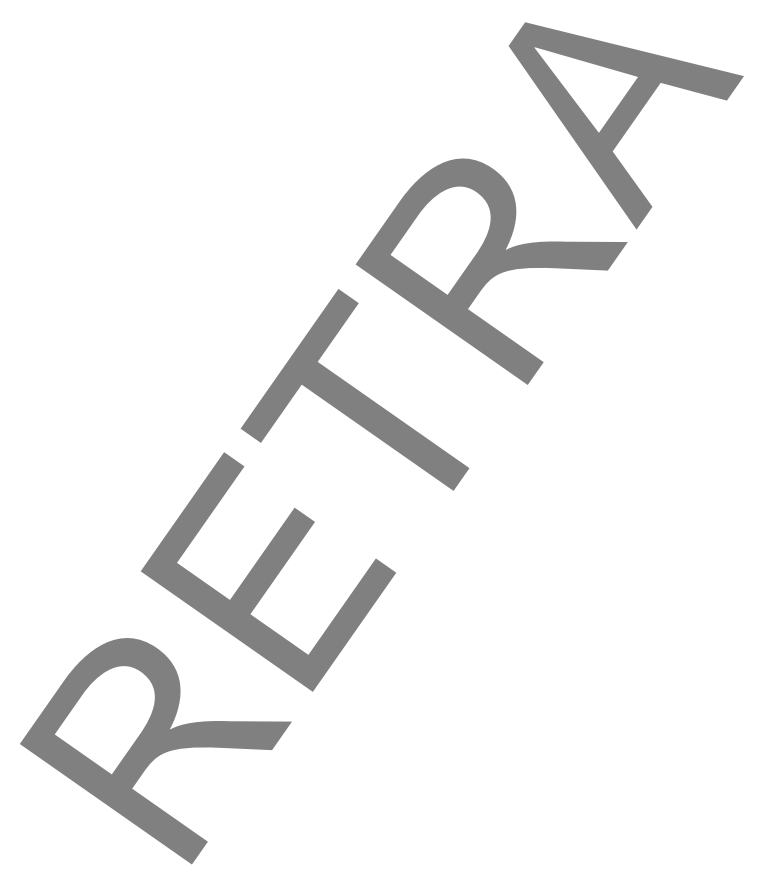

Rev. Bras. PI. Med., Botucatu, v.14, n.1, p.103-109, 2012. 